\title{
The Effect of Resilience on the Psychological Well Being of Orphan and Non-Orphan Adolescents
}

\author{
Priyanka Dey ${ }^{1}$, Beena Daliya R. ${ }^{2}$ \\ ${ }^{1}$ Student, M.Sc. Psychology, \\ ${ }^{2}$ Assistant Professor, Department of Psychology, \\ Indian Institute of Psychology and Research, Bangalore \\ Corresponding author: Priyanka Dey \\ Email-pdey74449@gmail.com
}

\begin{abstract}
Background: Resilient individuals are usually able to maintain their physical and psychological health and have the competence to recover quickly from stressful events. The present study provides insight into vulnerable segment of the population and helps to identify the factors contributing to their wellbeing $\&$ modifying them. Thus following this view, the objectives of the study was to examine the level of Resilience and psychological wellbeing among orphan and non-orphan adolescents; and to examine the influence of resilience on psychological wellbeing of orphan and non-orphan adolescents

Methodology: The participants were 30 orphan and 30 non-orphan adolescents (15 males \& 15 females in both group), aged 13-18 years and were administered Child and Youth Resilience Measure and Ryff's multidimensional Psychological wellbeing scale.

Results: The findings revealed that there is no significant difference in the level of Resilience among orphan and non-orphan adolescents where as there is significant difference in the Positive Relations with others among Orphan and Non orphan adolescents in the level of Psychological wellbeing. In relation to orphan adolescents, there is no significant influence of Resilience on psychological wellbeing of orphan adolescents whereas among non-orphan adolescents there was significant influence of Resilience on psychological wellbeing.

Conclusions: Further studies in diverse populations are warranted to ascertain the effects of Resilience on Psychological well being in adolescents.
\end{abstract}

Keywords: Resilience, Psychological wellbeing, Orphan, Non- Orphan adolescents.

(Paper received $-6^{\text {th }}$ August 2019 , Peer review completed $-9^{\text {th }}$ September 2019)

(Accepted $-10^{\text {th }}$ September 2019)

\section{INTRODUCTION}

Richardson and his colleagues [1] stated resiliency to be the process of coping with disruptive, stressful, or challenging life events in a way that provides the individual with additional protective and coping skills than prior to the disruption that results from the event. Resiliency has been linked with positive mood, positive self-esteem, feeling of self-efficacy, secure relationships [2-4]. According to researchers [5], psychological well-being is being able to feel good about one self and to be able to function effectively which involves having a sense of control over one's life, to be able to exploit one's potential, having a sense of purpose in life and experiencing positive relations with others. It has been found that secure attachment with parents, healthy peer relationships and a protective social environment help the person to resolve the problems with confidence; also develops various self-competencies as social-emotional skills, cognitive and occupational abilities and others [6-7]. Thus, resilient behaviour significantly contribute in psychological well-being of individuals that lead them to cope effectively with various situational contexts of life [8]. 
Resilience theory is a process of balancing the protective factors against risk factors [9-10], and the gradual accumulation of emotional strength as children respond successfully to challenges in their families, schools and communities [11].

Well-being is dynamic concept that includes subjective, social, and psychological dimensions as well as health related behaviours [12]. Ryff's model Psychological well-being theory states that the goal of life is about living virtuously instead of just feeling good.

Katyal [13] investigated- the resilience among orphan and non-orphan children. The study was carried out in orphanages and schools in Chandigarh, Panchkula and Ajitgarh (Mohali) in India. The sample consisted of 50 orphan children ( 25 from each orphanage) and 50 non-orphan children ( 25 from each school) aged 12 18 years. Standardized tools were used. Results indicated that there was significant difference in resilience of orphan and non-orphan children, with orphan children having higher resilience than that of non-orphan children mainly develops due to development of close and warm social bonds and friendships with peers in orphanages. Sreekanth and Verma [14] conducted a study comparing stress and psychological well-being among orphan and normal adolescence (40 orphans and 40 non orphans) in Adilabadh district, Telangana state, through accidental sampling. Stress scale by Sinha and PGI General Well-Being scale by Verma and Verma were used for measuring the level of stress and psychological well-being of orphan and normal adolescence. The study revealed that compared to normal adolescents, orphans are significantly more stressed and performed weakly in the areas of psychological wellbeing probably due to lack of parental care or lack of guidance, facilities, and negligence in orphanages. Also, orphans are neglected from fields of education, daily needs of adolescents, sports activities, lack of love and affection, compare to normal adolescents.

The present study will be helpful in understanding and would provide insight into vulnerable segment of the population. This will also help in identifying the factors contributing to their wellbeing \& modifying them. The present study would help in identifying the factors affecting their Psychological wellbeing. It will also help to develop effective intervention program to enhance the level of resilience and psychological wellbeing among them, providing psycho-education to parents and care givers. Most of the researches are conducted on western population suggesting a need for the present study from Indian context. The study would also add to the existing review of literature.

The aim of the study was to determine the effect of Resilience on the Psychological wellbeing of orphan and non-orphan adolescents. The objectives were to examine the level of resilience among orphan and nonorphan adolescents, to examine the level of psychological wellbeing among orphan and non-orphan adolescents, to examine the influence of resilience on psychological wellbeing of orphan adolescents and to examine the influence of resilience on psychological wellbeing of non-orphan adolescents

\section{METHODOLOGY}

The present study is based on survey method and is empirical in nature. The primary data was collected from orphan and non-orphan adolescents from Bangalore.

\section{Hypotheses}

- There is no significant difference in the level of resilience among orphan and non orphan adolescents

- There is no significant difference in the level of psychological wellbeing among orphan and non orphan adolescents

- There is no significant influence of resilience on psychological wellbeing of orphan adolescents

- There is no significant influence of resilience on psychological wellbeing of non - orphan adolescents Variables

Independent Variables: Adolescence (orphan and non-orphan)

Dependent Variables: Resilience, Psychological wellbeing.

Research Design: The research design employed for this study was non-experimental co-relational research design. Parametric statistics - Pearson's product moment correlation and Multiple Regression, Independent sample t-test and one-way multivariate analysis of variance (MANOVA) were used for analysing. 
Sample: Following purposive sampling technique, a total sample of 30 orphan adolescents (15 males and 15 females) and 30 non orphan adolescents (15 males and 15 females), living in Bangalore between the age group of 13-18 years were selected,

\section{Inclusion Criteria:}

- Male and female adolescents in the age range of 13-18 years

- Urban / sub- urban

- Delinquent/ under trial orphan adolescent

\section{Exclusion Criteria:}

- Single parent child.

- Adolescents with mental and chronic physical illness

- Residing in hostel or with any guardian

\section{Tools for Data Collection:}

- The 54 item scale Ryff's multi-dimensional Psychological wellbeing scale (1989) developed by Carol Ryff, measures the 6 dimensions of psychological well-being [15].

- The Child and Youth Resilience Measure (CYRM)-28 is a measure of youth resilience for the youth populations (aged 10-23) which has three sub-scales of individual capacities/ resources, relationships with primary caregivers and contextual factors that facilitate a sense of belonging [16].

Ethical Considerations: Informed consent was taken from the parent/guardian and the sample and confidentiality was ensured. It was ensured that no physical or emotional harm was caused to the participants during and after the research. None of the samples were forced to be a part of the research. The data obtained shall be used only for academic purpose. The participants were allowed to leave the research work if he /she wished to.

\section{RESULTS}

The table below shows a comprehensive overview of the descriptive statistics.

Table 1: Descriptive Statistics of Resilience and Psychological wellbeing in Orphan and Non orphan Adolescents.

\begin{tabular}{|c|c|c|c|c|c|}
\hline $\begin{array}{c}\text { Orphan \& non-orphan } \\
\text { adolescents }\end{array}$ & $\mathbf{N}$ & Mean & $\begin{array}{c}\text { Std. } \\
\text { Deviation }\end{array}$ & Kurtosis & Skewness \\
\hline Resilience & 30 & 115.55 & 13.472 & 0.208 & -0.903 \\
\hline Autonomy & 30 & 34.83 & 5.927 & 1.377 & 0.717 \\
\hline Environmental Mastery & 30 & 36.20 & 5.461 & -0.425 & -0.017 \\
\hline Personal Growth & 30 & 34.43 & 6.958 & -0.516 & 0.612 \\
\hline Positive relations with Others & 30 & 35.38 & 6.722 & -0.737 & 0.276 \\
\hline Purpose of Life & 30 & 36.22 & 7.820 & -0.697 & 0.051 \\
\hline Self Acceptance & 30 & 39.25 & 7.410 & -0.515 & -0.092 \\
\hline
\end{tabular}

In the table 1, descriptive statistics of Resilience and Psychological wellbeing in Orphan and Non orphan Adolescents are shown. For the total number of respondents, $(\mathrm{N}=60)$, a group of samples of 30 orphan adolescents and 30 non orphan adolescents were selected. The table shows the mean score, skewness and kurtosis value of Resilience and the variables of psychological wellbeing which are identified to be between the range of -1.96 to +1.96 , hence the distribution is normal. 
Table 2: Independent Sample t-Test - Level of Resilience among Orphan and Non-Orphan adolescents

In the table 2, Independent sample $t$ test scores for the level of Resilience among Orphan and Non orphan adolescents are shown. For this research sample $(n=60)$, the group of Orphan adolescents $(M=116.27, S D$ $=13.913, n=30)$ has higher Resilience than the group of Non orphan adolescents sample $(M=114.83, S D$ $=13.215, n=30), d f=58, t=-0.409, p=0.988$ and is not significant at 0.05 level. Therefore $p>0.01$, hence the null hypothesis is accepted and alternate hypothesis is rejected. Hence there is no significant difference in the level of Resilience among orphan and non-orphan adolescents. This can be due to the reason that the sample was from urban population and both orphan and non-orphan adolescents had proper education and their skills in communication, problem solving skills, and their confidence level was nurtured with immense care. It was also noted that both the groups of orphan and non-orphan had close and warm social bonds and friendships with peers in orphanages and back at their house. Generally, in urban setting, parents take care of their children a lot and also make them involve in many extra curriculum activities which makes them more trained to face challenges. Not only non orphan adolescents, but even in orphanages, various workshops, activities, visiting's, are conducted and children are exposed to challenges and guidance is given in every step which makes the orphan adolescents being equally resilient to non orphan adolescents.

\begin{tabular}{|c|c|c|c|c|c|c|c|}
\hline $\begin{array}{c}\text { Dependent } \\
\text { Variable }\end{array}$ & $\begin{array}{c}\text { Independent } \\
\text { Variable }\end{array}$ & $\mathbf{N}$ & Mean & $\begin{array}{c}\text { Std. } \\
\text { Deviation }\end{array}$ & $\mathbf{t}$ & df & Significance \\
\hline Resilience & $\begin{array}{c}\text { Orphan } \\
\text { Non orphan }\end{array}$ & $\begin{array}{l}30 \\
30\end{array}$ & $\begin{array}{l}116.27 \\
114.83\end{array}$ & $\begin{array}{l}13.913 \\
13.215\end{array}$ & -0.409 & 58 & 0.988 \\
\hline
\end{tabular}

Table 3: Descriptive Statistics and Levene's Test of Homogeneity level of Psychological wellbeing among Orphan and Non orphan adolescents

\begin{tabular}{|c|c|c|c|c|c|c|c|}
\hline \multirow[t]{2}{*}{$\begin{array}{l}\text { Dependent } \\
\text { Variable }\end{array}$} & \multirow[t]{2}{*}{ Adolescents } & \multirow[t]{2}{*}{ Mean } & \multirow[t]{2}{*}{$\begin{array}{l}\text { Std. } \\
\text { Deviation }\end{array}$} & \multirow[t]{2}{*}{$\mathbf{N}$} & \multicolumn{3}{|c|}{$\begin{array}{l}\text { Levene's Test Of Equality Of Error } \\
\text { Variances }\end{array}$} \\
\hline & & & & & $\mathbf{F}$ & df1, df2 & Significance \\
\hline \multirow{3}{*}{$\begin{array}{l}\text { Autonomy } \\
\text { Score }\end{array}$} & Non Orphan & 35.00 & 6.384 & 30 & \multirow[t]{3}{*}{0.530} & \multirow[t]{3}{*}{1,58} & \multirow[t]{3}{*}{0.470} \\
\hline & Orphan & 34.67 & 5.536 & 30 & & & \\
\hline & Total & 34.83 & 5.927 & 60 & & & \\
\hline \multirow{3}{*}{$\begin{array}{l}\text { Environmental } \\
\text { Mastery Score }\end{array}$} & Non Orphan & 37.20 & 4.475 & 30 & \multirow[t]{3}{*}{2.702} & \multirow[t]{3}{*}{1,58} & \multirow[t]{3}{*}{0.106} \\
\hline & Orphan & 35.20 & 6.211 & 30 & & & \\
\hline & Total & 36.20 & 5.461 & 60 & & & \\
\hline \multirow{3}{*}{$\begin{array}{l}\text { Personal } \\
\text { Growth Score }\end{array}$} & Non Orphan & 34.50 & 5.824 & 30 & \multirow[t]{3}{*}{6.042} & \multirow[t]{3}{*}{1,58} & \multirow[t]{3}{*}{0.017} \\
\hline & Orphan & 34.37 & 8.036 & 30 & & & \\
\hline & Total & 34.43 & 6.958 & 60 & & & \\
\hline \multirow{3}{*}{$\begin{array}{l}\text { Positive } \\
\text { Relations with } \\
\text { Others Scores }\end{array}$} & Non Orphan & 37.47 & 6.801 & 30 & \multirow[t]{3}{*}{0.348} & \multirow[t]{3}{*}{1,58} & \multirow[t]{3}{*}{0.557} \\
\hline & Orphan & 33.30 & 6.058 & 30 & & & \\
\hline & Total & 35.38 & 6.722 & 60 & & & \\
\hline \multirow{3}{*}{$\begin{array}{l}\text { Purpose Of Life } \\
\text { Scores }\end{array}$} & Non Orphan & 37.13 & 6.771 & 30 & \multirow[t]{3}{*}{2.909} & \multirow[t]{3}{*}{1,58} & \multirow[t]{3}{*}{0.093} \\
\hline & Orphan & 35.30 & 8.766 & 30 & & & \\
\hline & Total & 36.22 & 7.820 & 60 & & & \\
\hline \multirow{3}{*}{$\begin{array}{l}\text { Self Acceptance } \\
\text { Scores }\end{array}$} & Non Orphan & 39.87 & 7.276 & 30 & \multirow[t]{3}{*}{0.028} & \multirow[t]{3}{*}{1,58} & \multirow[t]{3}{*}{0.869} \\
\hline & Orphan & 38.63 & 7.613 & 30 & & & \\
\hline & Total & 39.25 & 7.410 & 60 & & & \\
\hline
\end{tabular}

In the table 3, the results of descriptive statistics and Levene's test of homogeneity for the level of Psychological wellbeing among orphan and non-orphan adolescents are shown. 
For the research sample $(n=60)$, the Levene's test of Equality of Error Variance of the dependent variables is homogeneous (Autonomy: $p=0.470$, Environmental Mastery: $p=0.106$, Positive Relations with others: $p=0.557$, purpose of life: $p=0.093 \&$ Self acceptance: $p=0.869)$ expect the Personal Growth $(p=0.017)$ which indicates that it is not homogenous.

Table 4: Box's Test of Equality of Covariance Matrices, Wilks' Lambda Multivariate Test -level of Psychological wellbeing among orphan and non orphan adolescents

\begin{tabular}{|c|c|c|c|c|c|c|c|c|c|}
\hline \multirow[t]{2}{*}{$\begin{array}{l}\text { Independent } \\
\text { Variable }\end{array}$} & \multirow{2}{*}{$\begin{array}{l}\text { Wilk's } \\
\text { Lambda } \\
\text { Value }\end{array}$} & \multirow[t]{2}{*}{$\mathbf{F}$} & \multirow[t]{2}{*}{$\begin{array}{l}\text { Hypothesis } \\
\text { df }\end{array}$} & \multirow[b]{2}{*}{ Sig. } & \multirow{2}{*}{$\begin{array}{l}\text { Partial } \\
\text { Eta } \\
\text { Squared } \\
\left(\Phi^{2}\right)\end{array}$} & \multicolumn{4}{|c|}{$\begin{array}{l}\text { Dependent Variable Box's Test of Equality of } \\
\text { Covariance Martrices }\end{array}$} \\
\hline & & & & & & $\begin{array}{l}\text { Box's } \\
\text { M }\end{array}$ & $\mathbf{F}$ & df1, df2 & Significance \\
\hline $\begin{array}{l}\text { Orphan and } \\
\text { Non-orphan } \\
\text { Adolescents }\end{array}$ & 0.828 & $1.834^{\mathrm{b}}$ & 6.000 & 0.110 & 0.172 & 42.093 & 1.781 & $\begin{array}{l}21 \\
12372.78\end{array}$ & $0.015^{*}$ \\
\hline
\end{tabular}

In the table 4, The Box's M Test of equality of co-variance matrices signifies that assumption of equality of co-variance matrices is significant (Box's $\mathrm{M}=42.093, \mathrm{~F}=1.781, \mathrm{df}=21,12372.787, \mathrm{p}=0.015$ which is < 0.05). The Multivariate test results shows that Orphan and non-orphan adolescents (Wilks' Lambda Value $=0.828, \mathrm{~F}=1.834, \mathrm{df}=6.000, \mathrm{p}=0.110, \mathrm{\Phi}^{2}=0.172$ ) has no significant influence on dependent variable.

Table 5: MANOVA (Tests of Between-Subjects Effects) -level of Psychological wellbeing among Orphan and Non-orphan adolescents

\begin{tabular}{|c|c|c|c|c|c|c|}
\hline Source & $\begin{array}{l}\text { Dependent } \\
\text { Variable }\end{array}$ & Df & $\begin{array}{l}\text { Mean } \\
\text { Square }\end{array}$ & $\mathbf{F}$ & Significance & $\begin{array}{l}\text { Partial Eta } \\
\text { Squared } \\
\left(\eta_{p}{ }^{2}\right)\end{array}$ \\
\hline \multirow{6}{*}{$\begin{array}{l}\text { Orphan and } \\
\text { Non } \\
\text { Orphan } \\
\text { Adolescents }\end{array}$} & Autonomy Score & 1 & 1.667 & 0.047 & 0.830 & 0.001 \\
\hline & $\begin{array}{l}\text { Environmental } \\
\text { Mastery Score }\end{array}$ & 1 & 60.000 & 2.048 & 0.158 & 0.034 \\
\hline & $\begin{array}{l}\text { Personal Growth } \\
\text { Score }\end{array}$ & 1 & 0.267 & 0.005 & 0.942 & 0.000 \\
\hline & $\begin{array}{l}\text { Positive Relations } \\
\text { With Others Score }\end{array}$ & 1 & 260.417 & 6.278 & 0.015 & 0.098 \\
\hline & $\begin{array}{l}\text { Purpose Of Life } \\
\text { Scores }\end{array}$ & 1 & 50.417 & 0.822 & 0.368 & 0.014 \\
\hline & $\begin{array}{l}\text { Self Acceptance } \\
\text { Score }\end{array}$ & 1 & 22.817 & 0.411 & 0.524 & 0.007 \\
\hline
\end{tabular}

In the table 5, The test Between-Subject Effects result describes that there is no significant difference in Autonomy ( $p=0.830)$; Environmental mastery ( $p=0.158$; Personal Growth $(p=0.942)$; Positive Relations with Others $(p=0.015)$; Purpose of life $(p=0.368)$; Self acceptance $(p=0.524)$ among Orphan and Non orphan Adolescents as $p>0.05$. Therefore, the null hypothesis is rejected and alternate hypothesis is accepted. Hence there is significant difference in the level of Psychological wellbeing among Orphan and Non orphan adolescents.

The variable "Positive Relation with others" indicated significant difference which may be due to the fact that non orphan adolescents experience warm, satisfying, and trusting relationships with peers and family members whereas in case of orphan adolescents, they have very few close and trusting relationships with others, they find difficulty to open up and feels isolated in interpersonal relationships. Researchers [17] believed that adolescents living in the intact families with their parents are found to have a better scholastic achievement, conduct, psychological adjustment, self-esteem and social competence which lower their 
psychological distress. Whereas adversities such as lack of parental and familial support initiate a major change in the lives of children [18] and can also interrupt their healthy psychological functioning [19].

Table 6: Pearson Product Moment Correlation Test - Resilience on Psychological wellbeing among orphan adolescents

\begin{tabular}{|l|l|l|l|l|l|}
\hline Resilience Score & Mean & $\begin{array}{l}\text { Std. } \\
\text { Deviation }\end{array}$ & $\mathbf{N}$ & $\begin{array}{l}\text { Pearson } \\
\text { Correlation }\end{array}$ & $\begin{array}{l}\text { Sig. } \\
\text { (2-tailed) }\end{array}$ \\
\hline Resilience score & 116.27 & 13.913 & & & \\
\hline Autonomy score & 34.67 & 5.536 & 30 & 0.075 & 0.693 \\
\hline Environmental mastery score & 35.20 & 6.211 & 30 & 0.176 & 0.353 \\
\hline Personal growth score & 34.37 & 8.036 & 30 & -0.113 & 0.550 \\
\hline Positive relations with others score & 33.30 & 6.058 & 30 & -0.237 & 0.206 \\
\hline Purpose of life score & 35.30 & 8.766 & 30 & -0.046 & 0.811 \\
\hline Self -Acceptance score & 38.63 & 7.613 & 30 & 0.050 & 0.794 \\
\hline
\end{tabular}

In the table 6, For this research sample $(n=30)$, the Resilience and Autonomy $(\mathrm{r}=0.075, \mathrm{p}=0.693)$; Environmental Mastery ( $r=0.176, p=0.353$ ); Personal growth $(r=-0.113, p=0.550)$; Positive Relations with others $(r=-0.237, p=0.206)$; Purpose of life $(r=-0.046, p=0.811)$; Self acceptance $(r=0.050, p=0.794)$ of the sample is not significant at 0.05 level as $p>0.05$. The results null hypothesis is accepted and hull hypothesis is rejected. Hence it revealed that there is no significant influence of Resilience on the psychological wellbeing of orphan adolescents. It indicates that this may be due to the circumstances prevalent in their orphanages where they develop resiliency in their behavior but they lack guidance and are neglected from the field of education, daily needs of adolescents, sports activities and many others [14]. Research indicates that Orphans have higher internalized problem compared to non-orphan adolescents and thereby influencing the psychological wellbeing. It is also seen from research studies that orphan are higher in resiliency but lower in psychological wellbeing when compared to non-orphan adolescents [13].

Table 7: Pearson Product Moment Correlation Test - Resilience and Psychological wellbeing

\begin{tabular}{|l|l|l|l|l|l|}
\hline Variables & Mean & $\begin{array}{l}\text { Std. } \\
\text { Deviation }\end{array}$ & N & $\begin{array}{l}\text { Pearson } \\
\text { Correlation }\end{array}$ & $\begin{array}{l}\text { Sig. } \\
\text { (2-tailed) }\end{array}$ \\
\hline Resilience score & 114.83 & 13.215 & \multicolumn{4}{|l|}{} \\
\hline Autonomy score & 35.00 & 6.384 & 30 & 0.300 & 0.108 \\
\hline Environmental mastery score & 37.20 & 4.475 & 30 & 0.579 & 0.001 \\
\hline Personal growth score & 34.50 & 5.824 & 30 & 0.473 & 0.008 \\
\hline Positive relations with others score & 37.47 & 6.801 & 30 & 0.513 & 0.004 \\
\hline Purpose of life score & 37.13 & 6.771 & 30 & 0.467 & 0.009 \\
\hline Self -Acceptance score & 39.87 & 7.276 & 30 & 0.491 & 0.006 \\
\hline
\end{tabular}

For this research sample $(n=30)$, the Resilience and Autonomy $(r=0.300, p=0.108)$ is significant at 0.05 level. Therefore $p>0.05$, there is no significant relationship between Resilience and Autonomy score among the non-orphan adolescents. Whereas, the Resilience and Environmental Mastery $(r=0.579, p=0.001)$; Personal growth $(r=0.473, p=0.008)$; Positive Relations with others $(r=0.513, p=0.004)$; Purpose of life $(r=$ $0.467, \mathrm{p}=0.009)$; Self acceptance $(\mathrm{r}=0.491, \mathrm{p}=0.006)$ of the sample is positively correlated and is significant at 0.05 level. Therefore $p<0.05$, there is significant relationship between Resilience and Environmental Mastery, Personal Growth, Positive Relations with others, Purpose of life and self-acceptance scores among the non-orphan adolescents whereas there is no significant relationship between resilience and autonomy. 
Table 8: Multiple Regressions - Resilience on Psychological wellbeing

\begin{tabular}{|l|l|l|l|l|l|l|l|}
\hline $\begin{array}{l}\text { Predictor } \\
\text { Variable }\end{array}$ & $\begin{array}{l}\text { Beta Standardized } \\
\text { Coefficient }\end{array}$ & Sig. & R & R Square & Df & F & Sig. \\
\hline Autonomy & 0.300 & 0.108 & 0.300 & 0.090 & 1,28 & 2.761 & 0.108 \\
\hline Environmental Mastery & 0.579 & 0.001 & 0.579 & 0.335 & 1,28 & 14.121 & 0.001 \\
\hline Personal Growth & 0.473 & 0.008 & 0.473 & 0.223 & 1,28 & 8.048 & 0.008 \\
\hline $\begin{array}{l}\text { Positive Relations with } \\
\text { others }\end{array}$ & 0.513 & 0.004 & 0.513 & 0.263 & 1,28 & 9.985 & 0.004 \\
\hline Purpose of life & 0.467 & 0.009 & 0.467 & 0.218 & 1,28 & 7.808 & 0.009 \\
\hline Self Acceptance & 0.491 & 0.006 & 0.491 & 0.241 & 1,28 & 8.897 & 0.006 \\
\hline
\end{tabular}

For this research sample $(n=30)$, the dimension of psychological well being - Autonomy $(\beta=0.300, \mathrm{p}=$ 0.108 ) is not a significant predictor for resilience among non-orphan adolescents. For this research sample $(n=30)$, the dimension of psychological Well Being-Environmental Mastery $(\beta=0.579, \mathrm{p}=0.001)$; Personal Growth $(\beta=0.473, p=0.008)$; Positive relations with others $(\beta=0.513, p=0.004)$; purpose of life $(\beta=0.467$, $\mathrm{p}=0.009)$; self acceptance $(\beta=0.491, \mathrm{p}=0.006)$ is a significant predictors for resilience among the nonorphan adolescents. Therefore, the null hypothesis is rejected and alternate hypothesis is accepted. There is significant influence of Resilience on Psychological wellbeing of non-orphan adolescents. The results indicate that Environmental Mastery, Positive relations with others, personal growth, purpose of life, selfacceptance will be able to predict relationship with resilience among the non-orphan adolescents.

Resilience is considered as one of the indicators of psychological well-being of the individuals [20]. Ryff and Singer [15] argue that resilient individuals are generally able to maintain their physical and psychological health and have the capacity to recover more quickly from stressful events. Researchers also found that adolescents living in the intact families with their parents have a better scholastic achievement, conduct, psychological adjustment, self-esteem and social competence lowering their psychological distress [17].

\section{CONCLUSION}

\section{Implications of the study}

The findings of this study would help in throwing light into certain neglected fields like education, daily need of adolescents, physical activities, lack of love and affection. Hence, assisting in enhancing the qualities lacking in the field, can help in effective Resilience and psychological wellbeing of both orphan and nonorphan adolescents. The results have implication for the government and other agencies to develop programs with holistic approach for orphans through various NGO's.

The present study is limited in its scope due to the small sample size of 60 participants. Rural population was not taken into account, was limited to school going adolescents (English medium \& Kannada medium) and did not cater to non-educated adolescents for diversity of responses which in turn limits it from generalisation to the population.

\section{Scope for Further Research}

The findings of the present research holds that Resilience is not the only factors to measure Psychological wellbeing and factors other than Resilience are required for further research. The present study is based on Bangalore region, thus the study can be widened in terms of the geographical area so that the sample size could be increased and can represent the wider section of the society.

\section{Conclusions}

The relevance of the present study in Indian context caters to adolescents, who characterized by immense and drastic changes in physiology, emotional maturity, psychological and social factors as well as the roles and responsibilities of the individuals. The present research indicated that though there was no difference in the level of Resilience among orphan and non-orphan adolescents, there were differences in orphan and 
non-orphan adolescents with respect to Positive relations with others in the level of psychological wellbeing. It revealed that Resilience has no influence of on the Psychological wellbeing of orphan adolescents. Whereas, Resilience had significant influence on the psychological wellbeing of non-orphan adolescents (Environmental Mastery, Personal Growth, Positive Relations with others, purpose of life, Self-acceptance). Research evidences suggest that cultural resources like families, schools and societies help the individuals to become more resilient whereas lack of all these supportive and protective factors tend to weaken inherent potential of the individuals to deal with unfavorable circumstances but may increase the level of autonomous dealing with adversities.

\section{REFERENCES}

1. Richardson GE, Neiger BL, Jensen S, Kumpfer KL. The resiliency model. Health Educ 1990;21(6):33-9.

2. Rutter M. Resilience in the face of adversity: Protective factors and resistance to psychiatric disorder. Br J Psychiatry 1985;147(6):598-611.

3. Folke C, Carpenter S, Walker B, Scheffer M, Chapin T, Rockström J. Resilience thinking: integrating resilience, adaptability and transformability. Ecology Society 2010;15(4):110-7.

4. Smith BW, Tooley EM, Christopher PJ, Kay VS. Resilience as the ability to bounce back from stress: A neglected personal resource? J Positive Psychol 2010;5(3):166-76.

5. Huppert FA, So TT. Flourishing across Europe: Application of a new conceptual framework for defining wellbeing. Soc Indicators Res 2013;110(3):837-61.

6. Appleyard K, Egeland B, van Dulmen MH, Alan Sroufe L. When more is not better: The role of cumulative risk in child behavior outcomes. J Child Psychol Psychiatry 2005;46(3):235-45.

7. Engel B. Eagle soaring: The power of the resilient self. J Psychosoc Nurs Ment Health Serv 2007;45(2):44-9.

8. Fredrickson BL, Tugade MM, Waugh CE, Larkin GR. What good are positive emotions in crisis? A prospective study of resilience and emotions following the terrorist attacks on the United States on September 11th, 2001. J Personal Soc Psychol 2003;84(2):365-71.

9. Greeff AP, Vansteenwegen A, Herbiest T. Indicators of family resilience after the death of a child. Omega J Death Dying 2011;63(4):343-58.

10. Bhana A, Bachoo $\mathrm{S}$. The determinants of family resilience among families in low-and middle-income contexts: a systematic literature review. South Afr J Psychol 2011;41(2):131-9.

11. Coutu DL. How resilience works. Harv Business Rev 2002;80(5):46-56.

12. Segrin C, Hanzal A, Donnerstein C, Taylor M, Domschke TJ. Social skills, psychological well-being, and the mediating role of perceived stress. Anx Stress Coping 2007;20(3):321-9.

13. Katyal S. Gender difference in resilience among undergraduate boys and girls with broken-heart. Indian J Positive Psychol 2014;5(4):505-10.

14. Heiman T. Parents of children with disabilities: Resilience, coping, and future expectations. J Dev Physical Disabil 2002;14(2):159-71.

15. Ryff CD. Psychological well-being in adult life. Curr Dir Psychol Sci 1995;4(4):99-104.

16. Ungar M, Liebenberg L. Assessing resilience across cultures using mixed methods: Construction of the child and youth resilience measure. J Mixed Methods Res 2011;5(2):126-49.

17. Goldstein S, Brooks RB. Resilience in children. New York: Springer; 2005.

18. Alvord MK, Grados JJ. Enhancing resilience in children: A proactive approach. Prof Pychol Res Pract 2005;36(3):238-45.

19. Masten AS, Best KM, Garmezy N. Resilience and development: Contributions from the study of children who overcome adversity. Dev Psychopath 1990;2(4):425-44.

20. Kansky J, Diener E. Benefits of well-being: Health, social relationships, work, and resilience. J Positive Psychol Wellbeing 2017;1(2):129-69.

$* * * * * * * * * * * * * * * * * * * * * * * * * * * * * * * * * * * *$

Acknowledgements - Nil

Conflict of Interest - Nil;

Funding - Nil 